\title{
Wintering in Europe instead of Africa enhances juvenile survival in a long-distance migrant
}

\author{
Shay Rotics ${ }^{a}{ }^{*}$, Sondra Turjeman ${ }^{a}$, Michael Kaatz ${ }^{b}$, Yehezkel S. Resheff ${ }^{\text {a, }}{ }^{\text {, }}$ \\ Damaris Zurell ${ }^{\mathrm{d}}$, Nir Sapir ${ }^{\mathrm{e}}$, Ute Eggers ${ }^{\mathrm{f}}$, Wolfgang Fiedler ${ }^{\mathrm{g}, \mathrm{h}}$, Andrea Flack ${ }^{\mathrm{g}, \mathrm{h}}$, \\ Florian Jeltsch ${ }^{\mathrm{f}, \mathrm{i}, \mathrm{j}}$, Martin Wikelski ${ }^{\mathrm{g}, \mathrm{h}}$, Ran Nathan ${ }^{\mathrm{a}}$
}

${ }^{a}$ Movement Ecology Laboratory, Department of Ecology, Evolution and Behaviour, Alexander Silberman Institute of Life Sciences, The Hebrew University of Jerusalem, Jerusalem, Israel

${ }^{\mathrm{b}}$ Vogelschutzwarte Storchenhof Loburg e.V., Loburg, Germany

${ }^{\mathrm{c}}$ Edmond and Lily Safra Center for Brain Sciences, The Hebrew University, Jerusalem, Israel

d Dynamic Macroecology, Department of Landscape Dynamics, Swiss Federal Research Institute WSL, Birmensdorf, Switzerland

e The Animal Flight Laboratory, Department of Evolutionary and Environmental Biology, University of Haifa, Haifa, Israel

${ }^{\mathrm{f}}$ Plant Ecology and Conservation Biology, Institute for Biochemistry and Biology, University of Potsdam, Potsdam, Germany

${ }^{\mathrm{g}}$ Department of Migration and Immuno-Ecology, Max-Planck-Institute for Ornithology, Radolfzell, Germany

h Department of Biology, University of Konstanz, Konstanz, Germany

${ }^{i}$ Berlin-Brandenburg Institute of Advanced Biodiversity Research (BBIB), Berlin, Germany

j ZALF, Leibniz-Centre for Agricultural Landscape Research, Müncheberg, Germany

Keywords:

bird migration

Ciconia ciconia

shortening migration

survival

white stork

wintering

\begin{abstract}
Increased human-induced environmental changes and global warming alter bird migration timing and routes. Recently, many Holarctic species, including white storks, Ciconia ciconia, were reported to overwinter at higher latitudes, closer to breeding grounds. We aimed to understand the causes and implications of this phenomenon by examining bird survival and behaviour during overwintering in Europe versus Africa. We compared GPS and body acceleration data of 54 juvenile (first-year) white storks that originated from the same European natal population and overwintered in Europe or Africa. All six juveniles that overwintered in Europe survived through their first year, which was significantly higher than only $38 \%$ of the 48 overwintering in the species' traditional grounds in Africa. During overwintering, storks in Europe differed from those in Africa by (1) reducing movement and foraging range, (2) spending less time flying and more time resting, thus using less energy (estimated from overall dynamic body acceleration) and (3) reducing foraging effort, while relying more on anthropogenic resources (landfills and agricultural areas). Timing affected overwintering site as juveniles that overwintered in Europe hatched and started migrating later. We emphasize, however, that late hatching by itself did not yield a survival benefit as not all late juveniles curtailed their migration. We suggest that wintering in Europe was less demanding compared to Africa which may explain the increased survival of juveniles that wintered in Europe. Our findings correspond to the general increase in the European wintering population of white storks, and shed light on the contemporary trend of shortened bird migration; a phenomenon with potentially broad ecological implications.
\end{abstract}

Bird migration provides access to seasonally abundant food resources while avoiding harsh winter conditions (Alerstam, Hedenström, \& Åkesson, 2003; Somveille, Rodrigues, \& Manica, 2015). However, environmental conditions are changing

\footnotetext{
* Correspondence: S. Rotics, Movement Ecology Laboratory, Department of Ecology, Evolution and Behaviour, Alexander Silberman Institute of Life Sciences, The Hebrew University of Jerusalem, Givat Ram, Jerusalem 91904, Israel.
} E-mail address: shay.rotics@mail.huji.ac.il (S. Rotics). considerably as human-related food resources increase (Oro, Genovart, Tavecchia, Fowler, \& Martínez-Abraín, 2013) and the global climate is warming (IPCC, 2014). Plasticity of bird migration (Able \& Belthoff, 1998; Alerstam et al., 2003; Berthold, 1998) allows species to respond to these changes by altering migration timing and routes (Charmantier \& Gienapp, 2014; Newton, 2008). In many Holarctic bird species, migration phenology is adjusting towards an earlier arrival to breeding grounds to accommodate the earlier onset of spring (Both, Bouwhuis, Lessells, \& Visser, 2006; Hüppop \& 
Hüppop, 2003; Marra, Francis, Mulvihill, \& Moore, 2005; Newton, 2008).

In recent years, an increasing number of studies have also reported that Holarctic migrants are shortening their migration and overwinter at higher latitudes closer to their breeding grounds ( 28 species reviewed in Ambrosini et al., 2016; Newton, 2008; PavónJordán et al., 2015; Plummer, Siriwardena, Conway, Risely, \& Toms, 2015; Visser, Perdeck, van Balen, \& Both, 2009). Some overwinter in sites where they were not previously recorded and, for others, an increased proportion of the population winters at higher latitudes (Newton, 2008; Ramo et al., 2015). Accordingly, in several European migrants that overwinter both in Africa and in Europe, the European overwintering populations are growing (Gordo, Sanz, \& Lobo, 2007; Lok, Overdijk, Tinbergen, \& Piersma, 2011), probably due to anthropogenic (e.g. landfills and agriculture) food exploitation (Oro et al., 2013; Plummer et al., 2015; Ramos, Ramírez, Sanpera, Jover, \& Ruiz, 2009; Sanz-Aguilar, Jovani, Melián, Pradel, \& Tella, 2015; Tortosa, Caballero, \& Reyes-López, 2002) and the effects of milder winters that increase bird survival (Adriaensen \& Dhondt, 1990; Ambrosini et al., 2016; Duriez, Ens, Choquet, Pradel, \& Klaassen, 2012; Salewski, Hochachka, \& Fiedler, 2013). Conditions at wintering sites have a significant impact on birds' annual survival (Schaub, Kania, \& Köppen, 2005; Szostek \& Becker, 2015) with major consequences for population dynamics (Alves et al., 2013; Goodenough, Elliot, \& Hart, 2009; Ockendon, Hewson, Johnston, \& Atkinson, 2012; Schaub et al., 2005) and may trigger changes in migration patterns (Cooper, Sherry, \& Marra, 2015; McKellar, Marra, Hannon, Studds, \& Ratcliffe, 2013). It is therefore important to study the causes and implications of changes in overwintering patterns.

Recent intriguing findings suggest that birds that shorten their migration to overwinter closer to natal grounds in Europe attain higher survival than conspecifics wintering in traditional overwintering grounds in Africa (Lok et al., 2011; Sanz-Aguilar, Béchet, Germain, Johnson, \& Pradel, 2012, Sanz-Aguilar, De Pablo, \& Donázar, 2015). However, the underlying mechanisms could not be assessed from these studies which relied on 'mark-resight' methodology. Behavioural data linking recent changes in environmental conditions and bird overwintering shifts are lacking. Here, we aimed to address this gap by comparing GPS and body acceleration (ACC) data of juvenile (first-year) white storks, Ciconia ciconia, that overwintered in Europe and Africa.

We studied a stork population that mostly migrates from Europe to Africa (Berthold et al., 2001) along the eastern migratory flyway, via the Middle East, unlike western flyway migrants reported in the studies mentioned above. Storks are opportunistic predators (Bocheński \& Jerzak, 2006; Tsachalidis \& Goutner, 2002) and, recently, an increasing number of individuals have shortened their migrations to overwinter in southern Europe, particularly in Spain (Gordo et al., 2007; Martín, Onrubia, de la Cruz, \& Ferrer, 2016; Shephard, Rycken, Almalik, Struyf, \& Van Erp-van der Kooij, 2015; Tortosa et al., 2002) where they utilize landfills and an invasive crayfish Procambarus clarkii in rice fields (Aguirre \& Vergara, 2007; Peris, 2003; Sanz-Aguilar, Jovani, et al., 2015). To increase our understanding of this contemporary change, we examined differences in survival and behaviour between juvenile storks originating from the same natal region in Germany that overwintered in Europe and Africa. We devised two opposing hypotheses. (1) Survival of African wintering storks should be higher in accordance with the fact that most of the stork population migrate to Africa, where environmental conditions during the northern hemisphere winter are likely to be more suitable. In contrast, (2) the recent increase in the proportion of storks wintering in Europe (Gordo et al., 2007) implies a survival benefit, as has been evident in other migrating species (Lok et al., 2011; Sanz-Aguilar et al., 2012), possibly because of access to sufficient anthropogenic food resources (e.g. landfills) in Europe along with lower costs (flight) and risks (predation, hunting) than when wintering in Africa. We used advanced GPSbody acceleration (ACC) transmitters to compare survival, movement patterns, behaviour, activity-related energy expenditure (derived from overall dynamic body acceleration, ODBA; Wilson et al., 2006) and habitat use during overwintering in Europe versus Africa, aiming to elucidate possible fitness-related differences. We further examined why certain juveniles overwintered in Europe while others overwintered in Africa, testing the hypothesis that late-hatching juveniles, being less fit for the migration (Brown, Roche, \& O'Brien, 2015; McKim-Louder, Hoover, Benson, \& Schelsky, 2013; Mitchell, Guglielmo, Wheelwright, Freeman-Gallant, \& Norris, 2011), were more likely to shorten their journeys and overwinter in Europe.

\section{METHODS}

We tagged 92 juvenile storks. For this paper, we analysed data from 54 individuals that reached the wintering period, i.e. survived beyond October (a month after the end of last migratory journey to Africa); more details on the excluded individuals are given in Appendix 1. Juveniles were fitted with solar-charged GPS transmitters ( 48 from e-obs $\mathrm{GmbH}$, Munich, Germany, weight $54 \mathrm{~g}$, and six from Microwave Telemetry, Inc., Columbia, MD, U.S.A., weight $43 \mathrm{~g}$ ). Juveniles were trapped in their nests approximately a week prior to fledging, and tagging took place from 2011 to 2014 in the state of Saxony-Anhalt, Germany around three sites: Beuster $\left(52.939^{\circ} \mathrm{N}, 11.787^{\circ} \mathrm{E}\right)$, Loburg $\left(52.118^{\circ} \mathrm{N}, 12.087^{\circ} \mathrm{E}\right)$ and the Drömling Nature Park $\left(52.489^{\circ} \mathrm{N}, 11.022^{\circ} \mathrm{E}\right)$. The transmitter plus harness $(12 \mathrm{~g})$ weighed a maximum of $66 \mathrm{~g}$, corresponding to $2 \%$ of the mean white stork body mass (Bruderer, Peter, Boldt, \& Liechti, 2010).

The transmitters yielded two types of data sets: (1) lowresolution GPS data of 2-10 GPS fixes per day, transmitted remotely via cellular (e-obs tags) or satellite (Microwave tags) communication (see Appendix 2 for details); (2) high-resolution GPS and ACC data recorded every 5 min (e-obs tags only; when solar power was sufficient) from 0200 to 2000 GMT. The ACC was recorded for $3.8 \mathrm{~s}$ at $10.54 \mathrm{~Hz}$ for each of the three perpendicular axes, totalling 120 data points per ACC sample. The high-resolution data were stored on board the transmitters and were downloaded manually via radio link from approximately $300 \mathrm{~m}$ away (see Appendix 2); this was not feasible for all individuals.

Comparison of survival rates between storks wintering in Europe $(N=6)$ and Africa $(N=48)$ was based on the low-resolution GPS data. To compare fine-scale overwintering movement and behaviour, we examined the GPS-ACC high-resolution data from October to December of juveniles overwintering in Europe $(N=6)$ and Africa $(N=16)$ that survived throughout this period. We focused on this period because (1) all tracked individuals reached their overwintering grounds by October and (2) our transmitters depended on solar recharge, so low solar conditions resulted in highly fragmented data in January-February in Europe. Accordingly, solar conditions and sampling rates were higher in Africa than Europe. To eliminate this bias, we subsampled the data of the African wintering (AFW) juveniles in line with the European wintering (EUW) juveniles' data (see Appendix 3 for details). This resulted in a total of 347392 GPS-ACC records from 1760 wintering days of six EUW juveniles and 16 AFW juveniles. Because white storks are diurnal, and daylight time was shorter for individuals overwintering in Europe, in relevant analyses we examined daylight data (from half an hour before sunrise to half an hour after sunset) that was extracted using the Matlab 'suncycle' function 
(Pawlowicz, 2009). Data processing and analysis were done using Matlab (version R2013b, The MathWorks, Inc., Natick, MA, U.S.A.).

\section{Survival}

We compared first-year survival (binary, dead or alive) of juveniles wintering in Europe and Africa. Bird mortality was determined when a series of fixed positions was sent continuously over several days (mostly more than 5 ), indicating no movement of the individual (within a buffer of $75 \mathrm{~m}$ ). When transmitters were retrieved, mortality was verified based on the stork's remains and information from the finders.

The e-obs transmitters relied on cellular communication, and thus could not deliver data when the storks ranged in areas devoid of cellular coverage. In cases where transmitters stopped sending data suddenly without indication of mortality the respective storks were defined as 'missing'. No signal was received from the missing storks for more than 18 months and we presume they most likely died in an area without reception (see Appendix 4). Therefore, we assume it is more valid to refer to $90 \%$ of the missing storks as dead (in line with estimated tag malfunction rate, see Appendix 4) rather than to omit them from survival analysis. Both options were tested during analysis of stork survival.

\section{Movement Parameters}

Daily displacement was calculated from the distance between two consecutive roosting locations (determined daily from bird location at 0200 GMT). Stationary days were defined as days with less than $10 \mathrm{~km}$ of displacement and large-progression days as those with more than $50 \mathrm{~km}$ of displacement. Daily distance is the accumulated distance between all successive records of a given day. To test for spatial differences in foraging, utilization areas $(90 \%$ kernels) were estimated based on the r-LoCoH method (Getz et al., 2007) with $r=10 \mathrm{~km}$ (radius of records to be included in each point kernel construction) using the adehabitatHR package (Calenge, 2006) in R ( $\mathrm{R}$ Core Team, 2016). Only daytime nonflight records (speed $<5 \mathrm{~m} / \mathrm{s}$ ) were included as white storks forage on the ground.

\section{Activity-related Energy Expenditure and Behavioural Parameters}

ODBA has been found to be a valid estimator of activity-related energy expenditure (Halsey et al., 2008; Wilson et al., 2006). For each ACC sample, we calculated the ODBA value by subtracting each data point from a running average of $1 \mathrm{~s}$, and summing the resulting absolute values across axes.

We assessed bird behaviour by classifying the ACC records to seven behavioural modes using a supervised machine-learning algorithm (radial-basis-function kernel support vector machine) with a training set of 3815 ground-truthed ACC records of known behaviours; classification accuracy was 92\% (see Rotics et al., 2016 for details). We focused on three main behavioural categories: flight (flapping and gliding), resting (standing, sitting and preening) and foraging (walking and pecking). We refer to walking as part of the foraging activity because (1) storks catch prey while walking (Bocheński \& Jerzak, 2006; Carrascal, Alonso, \& Alonso, 1990), (2) our observational records indicate that $76 \%$ of the pecking events occurred while walking, and (3) storks typically fly rather than walk to cover short distances (S. Rotics, field observations). Additionally, we examined the pecking ratio defined as pecking records/(walking and pecking records).

\section{Land use and Ambient Temperature}

For each GPS fix, land use data were interpolated (nearestneighbour) using Movebank's Env-DATA track annotation tool (Dodge et al., 2013) based on the ESA GlobCover 2009 Project (ESA 2010 and UCLouvain, spatial resolution of $300 \mathrm{~m}$ and temporal resolution of 8 days). The land use classes displayed here originated from GlobCover land classes (Table A1 specifies the relations). We further examined landfill utilization through visual identification of relevant rubbish dump sites while examining storks' tracks in Google Earth. Only daylight nonflight records were used for these analyses.

We annotated ambient temperature per $\mathrm{h}$ on each tracking day using Movebank's Env-DATA track annotation tool (Dodge et al., 2013) based on weather data from the European Centre for Medium-Range Weather Forecasts (ECMWF) Global Atmospheric Reanalysis (temporal resolution of $6 \mathrm{~h}$ and spatial resolution of $0.7^{\circ}$ ).

\section{Hatching Date, Migration Onset and Premigration Experience}

We examined whether hatching date, migration onset and premigration experience affected overwintering location (Europe or Africa). Previous monitoring of bill growth during stork nestling development (Tsachalidis, Liordos, \& Goutner, 2005) allowed us to estimate hatching date based on the bill length measured during juvenile tagging. Juvenile migration start date was defined as the first day of more than $100 \mathrm{~km}$ displacement southwards $\left(100-260^{\circ}\right.$ azimuth) from the breeding grounds. Premigration experience was deduced from (1) the number of days between fledging and migration onset, where fledging date was conservatively defined as the first of 2 consecutive days in which the juvenile was away from the nest (distance $>100 \mathrm{~m}$ ) for at least $20 \mathrm{~min}$ and (2) total premigration flight time (number of records with speed $>5 \mathrm{~m} / \mathrm{s}$; each equivalent to $5 \mathrm{~min}$, in line with the sampling rate).

\section{Statistical Analysis}

Prior to applying parametric tests, normal distribution was verified using Lilliefors test and in relevant cases data were transformed using Box-Cox transformation. Proportion data were transformed using arcsine. Comparisons of EUW and AFW storks were conducted using $t$ tests and Wilcoxon rank sum tests. The influence of hatching date and migration onset on determining the wintering site (Europe or Africa) was tested with a general linear model (GLM) with binomial error distribution and logit link function. Similarly, migration onset effect on wintering storks' first-year survival (binary variable: dead or alive) was examined using a GLM with binomial error distribution and logit link function. Analyses were conducted using the statistics toolbox of Matlab (version R2013b, The MathWorks, Inc.). Results are reported by their mean \pm SE unless specified otherwise.

\section{Ethical Note}

Nestlings were taken from their nests using a cherry picker. Tagging and handling were done on the ground, lasted ca. 30 min and then the nestlings were returned immediately to the nest. In four cases nestlings fledged upon approaching the nest and were caught on the ground or returned to the nest on their own. No bird was injured during the trapping and tagging procedure. The research was carried out with approvals from the National Administrative Office of Sachsen-Anhalt, Germany, Division of Nature Conservation, 407.3.3/255.13-2248/2 and the State Office for Environment, Health and Consumer Protection of Brandenburg, Germany, V3-2347-8-2012. 


\section{RESULTS}

Survival

Fifty-four juveniles survived longer than the first month of overwintering (October), out of which six wintered in Europe and 48 in Africa (Table 1). All European wintering juveniles survived through their first year of life compared to $38.2 \%$ of the African wintering juveniles (Fisher exact test: $P=0.007$; Table 1). Furthermore, AFW storks' annual survival dropped to $29.2 \%$ when $90 \%$ of the 'missing' individuals were classified as dead, increasing the survival differences (Fisher exact test: $P=0.001$; Table 1 ).

\section{Movement}

EUW storks made smaller daily displacements, moved shorter daily distances, had a higher ratio of stationary days, a lower ratio of large-progression days and a much smaller habitat utilization area than AFW storks (Fig. 1, Table 2). Even on stationary days, EUW storks covered less daily distance than AFW storks (Table 2).

\section{ODBA and Behaviour}

EUW juveniles had significantly lower ODBA values than AFW juveniles ( $t$ test: $t_{20}=4.17, P<0.001$; Fig. 2 ) indicating lower activity-related energy expenditure. This is probably because EUW storks flew less $\left(t\right.$ test: $\left.t_{20}=11.58, P<0.001\right)$ and rested more $\left(t_{20}=5.28, P<0.001\right)$ while relative foraging time did not differ $\left(t_{20}=0.18, P=0.86\right.$; Fig. 3 ). Results did not change qualitatively when only daylight time data were examined (Table 3 ) or when only stationary days were analysed (Table A2).

Focusing only on foraging activity, EUW storks, again, had lower foraging ODBA than AFW storks (EUW: $2.27 \pm 0.10 \mathrm{~m} / \mathrm{s}^{2}$; AFW: $2.66 \pm 0.06 \mathrm{~m} / \mathrm{s}^{2} ; t$ test: $\left.t_{20}=3.33, P=0.003\right)$. This could be related to their marginally significantly higher pecking ratio during foraging (EUW: $0.47 \pm 0.05$; AFW: $0.37 \pm 0.02$; $t$ test: $t_{20}=2.02$, $P=0.06)$.

\section{Land use and Ambient Temperature}

EUW juveniles used more cropland areas ( $t$ test: $t_{20}=8.83$, $P<0.001)$ and less wild areas of shrub and grassland than AFW juveniles ( $t$ test: $t_{20}=9.14, P<0.001$; Fig. 4 ). Three of the six EUW storks relied on rubbish dumps, spending $38.2 \pm 15.3 \%$ (mean \pm SD) of total daylight time and $40.7 \pm 7.5 \%$ of their foraging time inside or less than $100 \mathrm{~m}$ from landfills. Among the remaining three individuals: one relied intensively on a refuse site during Januar$\mathrm{y}$-February (spending $29.3 \%$ and $65.6 \%$ of daylight and foraging time, respectively, at a waste site in Croatia) and another was regularly fed by locals in southern Germany ( $\mathrm{H}$. Schmid, personal communication). Landfill utilization was not detected for the AFW storks $(N=16)$.

EUW storks experienced significantly lower ambient temperatures than AFW storks during October-December (EUW: $10.5{ }^{\circ} \mathrm{C} \pm 1.3$; AFW: $25.3^{\circ} \mathrm{C} \pm 0.5$; $t$ test: $t_{20}=5.0, P<0.001$ ).

Table 1

First-year survival of juveniles that overwintered in Europe versus Africa

\begin{tabular}{lllll}
\hline & $\begin{array}{l}\text { Wintering } \\
\text { individuals }\end{array}$ & $\begin{array}{l}\text { Survived the } \\
\text { first year }\end{array}$ & $\begin{array}{l}\text { Died during } \\
\text { first year }\end{array}$ & Missing \\
\hline Europe & 6 & 6 & 0 & 0 \\
Africa & 48 & 13 & 21 & 14 \\
\hline
\end{tabular}

Missing: tag transmission stopped without prior indication of mortality; see Methods for details.
Factors Affecting Wintering Location

EUW storks hatched later (Fig. 5 ; $t$ test: $t_{52}=2.62, P=0.011$ ) and started migrating later than AFW storks (Fig. 5; Wilcoxon rank sum test: $z=3.1, N=54, P=0.002$ ). Comparing GLMs of these factors together and each one separately on determining the wintering location (Europe or Africa) revealed that the best model (based on corrected Akaike information criterion scores) included only migration onset (GLM: Wald $\chi_{1}^{2}=5.44, P=0.020$ ). Even though late migration was associated with wintering in Europe, migration onset time was not found to influence whether the juveniles survived their first year (GLM: Wald $\chi_{1}^{2}=1.66, P=0.2$ ).

The age at migration onset was not different between EUW and AFW juveniles (EUW: $72.7 \pm 5.2$ days; AFW: $73.3 \pm 1.6$; $t$ test: $\left.t_{52}=0.17, P=0.86\right)$, nor was premigration experience, as deduced from both the number of days between fledging and migration (EUW median: 8.5 days; AFW: 13.5; Wilcoxon rank sum test: $z=0.84, N=54, P=0.4$ ) and from total premigration flight time (EUW: $10.4 \pm 2.1$ h; AFW: $12.2 \pm 1.7 \mathrm{~h}$; $t$ test: $t_{34}=0.14, P=0.89$ ).

\section{DISCUSSION}

Juvenile storks that overwintered in Europe closer to their natal grounds attained higher survival than most juveniles that overwintered in the species' traditional wintering grounds in Africa. Similar survival benefits were found for flamingos, Phoenicopterus roseus, and spoonbills, Platalea leucorodia, that overwintered at higher latitudes as deduced from ring recovery data (Lok et al., 2011; Sanz-Aguilar et al., 2012), but our tracking data revealed multiple behavioural and energetic differences that could be associated with the higher survival of EUW juveniles. These findings further our understanding of birds' shortening of migration routes and overwintering at higher latitudes.

Storks wintering in Europe were much more localized than AFW storks, displaying reduced movement and smaller foraging habitats. Accordingly, EUW storks spent less time on flight and more on resting and, consequently, had lower activity-related energy expenditure (estimated from ODBA). Correspondingly, reduced energy expenditure while curtailing migration have also been reported in other white stork populations (Flack et al., 2016).

Moreover, during the foraging activity itself, the energy expenditure of EUW juveniles was lower than that of AFW juveniles. EUW storks foraged more at human-related habitats (agricultural areas and rubbish dumps), which was apparently less demanding than catching prey in the wild. Lower daily distance covered within wintering sites in Europe and a possibly higher pecking ratio during foraging further support this conclusion. We suggest that utilizing human-related resources, and particularly landfills, by various birds (e.g. storks: Tortosa et al., 2002, gulls: Oro et al., 2013, kites: De Giacomo \& Guerrieri, 2008; eagles: Turrin, Watts, \& Mojica, 2015) provides a low-cost food resource. Accordingly, fitness benefits of exploiting anthropogenic food subsidies have been found in several species (Oro et al., 2013).

It was not possible to estimate the nutritional intake during foraging because the storks' pecking success and food items consumed could not be determined. Nevertheless, it was sufficient for the EUW juveniles as they all survived the winter, possibly assisted by storks' well-developed metabolic adaptations to starvation (Mata, Caloin, Michard-Picamelot, Ancel, \& Le Maho, 2001). Our findings point to EUW juveniles expending less activity-related energy than AFW juveniles while acquiring enough food for survival. Note, however, that we used ODBA measurements, which do not capture metabolic costs related to thermoregulation, digestion and immune responses. EUW storks faced colder weather which has been found to increase basal metabolic rate in passerines 


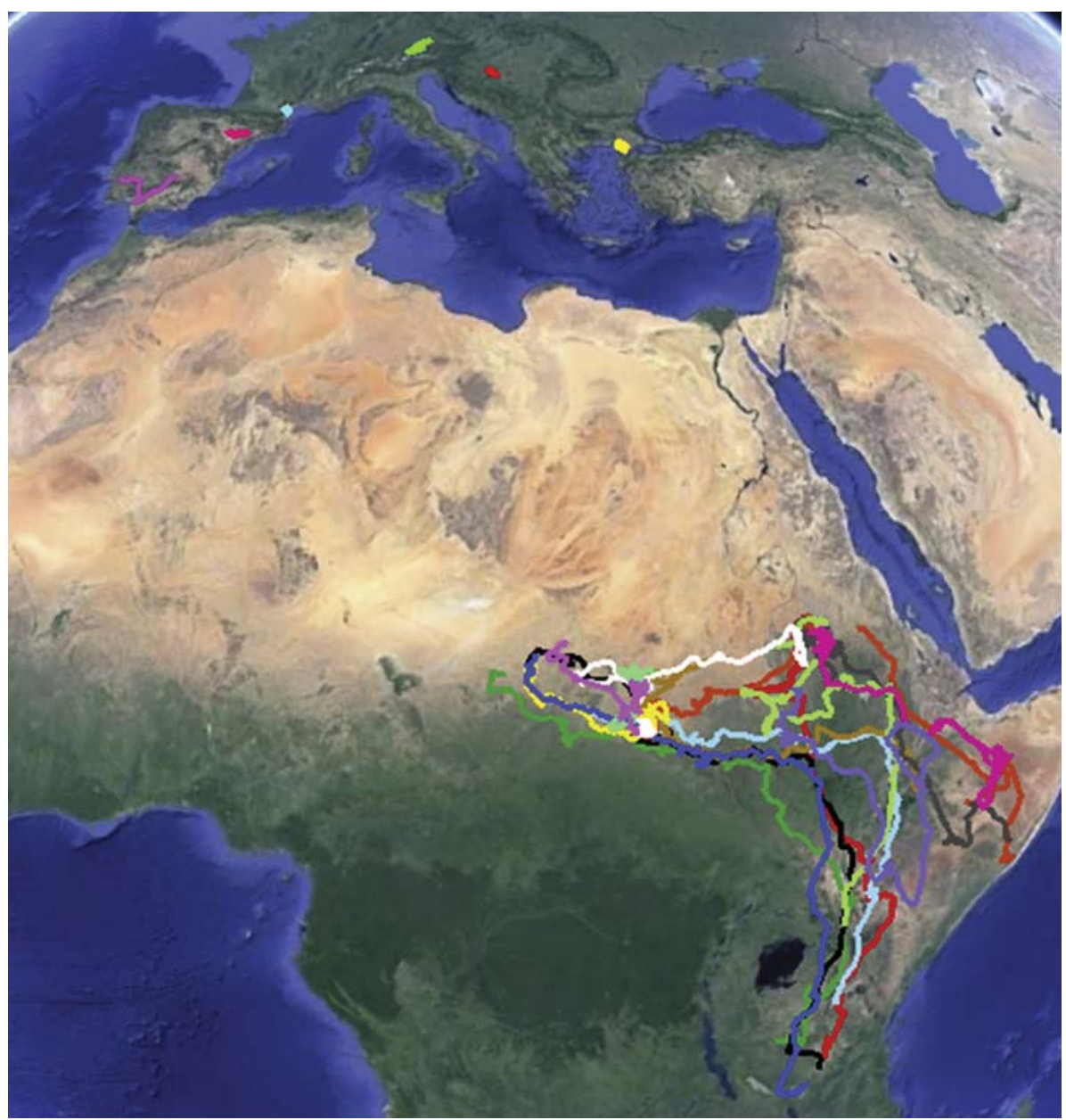

Figure 1. Tracks of 22 juvenile storks during wintering (October-December) in Europe $(N=6)$ and Africa $(N=16)$. EUW storks' lines are 1.5 times bolder to facilitate their visibility. Map () Google Earth.

(Swanson \& Olmstead, 1999) even though this effect is less pronounced in larger birds including storks (Mata, Massemin-Challet, Caloin, Michard-Picamelot, \& Le Maho, 2010; Swanson \& Weinacht, 1997); furthermore, digestion and immune costs might also differ while feeding on waste. Nevertheless, we suggest that reduced activity-related energetic costs while wintering in Europe through utilization of anthropogenic resources could be a significant cause of the EUW storks' elevated survival rates. Previous studies indeed suggest an inverse relationship between energy expenditure and survival in birds (Daan, Deerenberg, \& Dijkstra, 1996; Sala, Wilson, \& Quintana, 2015). Survival could also be affected by differences in the movement patterns, regardless of their energetic cost. AFW storks exhibited more long-range

Table 2

Movement parameters (mean $\pm \mathrm{SE}$ ) of EUW versus AFW storks during October-December

\begin{tabular}{llll}
\hline Parameter & EUW $(N=6)$ & AFW $(N=16)$ & Statistic \\
\hline Daily displacement $(\mathrm{km})$ & $4.2 \pm 1.2$ & $40.5 \pm 2.6$ & $t=12.9^{*}$ \\
Daily distance $(\mathrm{km})$ & $17.6 \pm 1.6$ & $90.4 \pm 5.3$ & $t=13.2^{*}$ \\
Daily distance in stationary & $13.9 \pm 2$ & $50.1 \pm 5.1$ & $t=6.4^{*}$ \\
$\quad$ days $(\mathrm{km})$ & $93.5 \pm 2.4$ & $45.9 \pm 2.4$ & \\
Stationary days $(\%)$ & $2.2 \pm 1.1$ & $24 \pm 1.6$ & $z=3.5^{*}$ \\
Large-progression days $(\%)$ & $183.8 \pm 64.5$ & $1643.2 \pm 236.2$ & $z=3.5^{*}$ \\
\hline Utilization area $\left(\mathrm{km}^{2}\right)$ &
\end{tabular}

Results of Student's $t$ tests $(t, d f=20)$ and Wilcoxon rank sum tests $(z)$. ${ }^{*} P<0.001$. movements which increase the risks and difficulties involved in reaching new, unfamiliar environments (Greenwood, 1980).

Other factors relevant to survival differ between the overwintering strategies: overwintering in Africa entails a longer, more

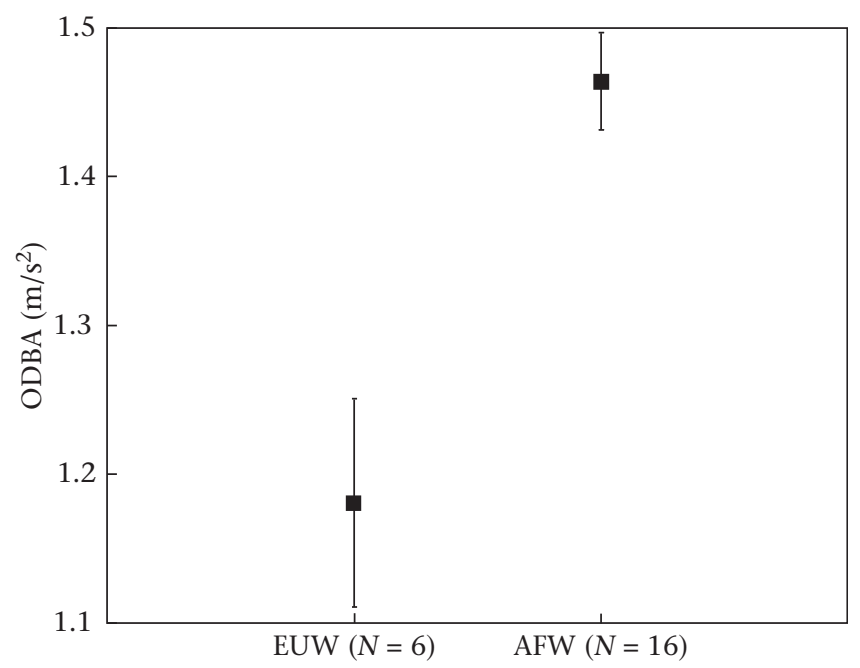

Figure 2. Overall dynamic body acceleration (ODBA) values (mean $\pm \mathrm{SE}$ ) for storks wintering in Europe (EUW) versus Africa (AFW). 

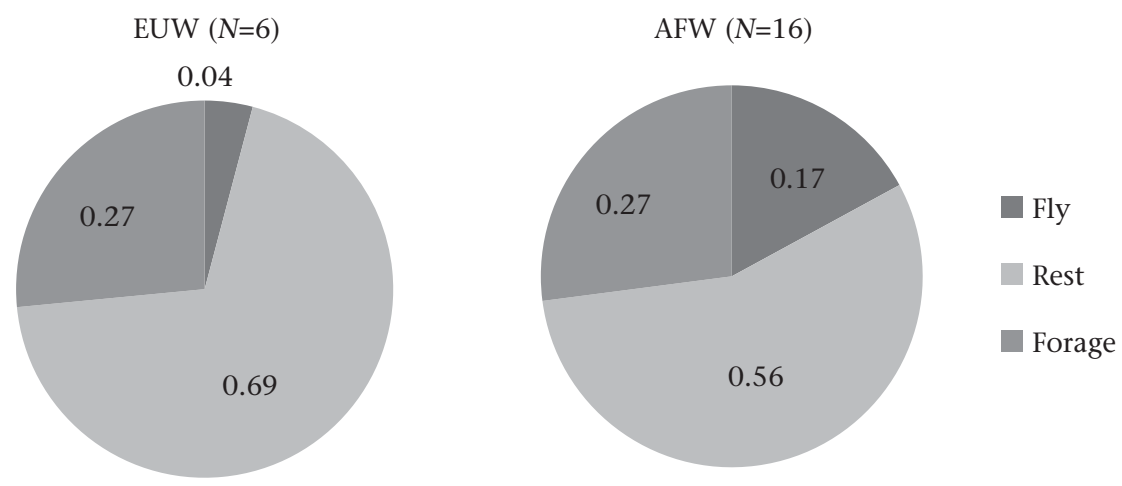

Figure 3. Distributions of behaviours of storks wintering in Europe (EUW) versus Africa (AFW).

Table 3

Comparisons of overall dynamic body acceleration (ODBA) and behavioural proportions during daylight hours between EUW and AFW storks

\begin{tabular}{lllll}
\hline Parameter & EUW $(N=6)$ & AFW $(N=16)$ & $t$ & $P$ \\
\hline ODBA $\left(\mathrm{m} / \mathrm{s}^{2}\right)$ & $1.66 \pm 0.11$ & $1.90 \pm 0.04$ & 2.61 & 0.017 \\
Relative flight time (\%) & $6.4 \pm 0.7$ & $24.5 \pm 1$ & 10.73 & $<0.001$ \\
Relative resting time (\%) & $52.4 \pm 4.2$ & $38.1 \pm 1.6$ & 3.88 & $<0.001$ \\
Relative foraging time (\%) & $41.2 \pm 4.8$ & $37.4 \pm 1.7$ & 0.97 & 0.35 \\
\hline
\end{tabular}

Mean \pm SE are reported. Statistical results are for Student's $t$ tests $(d f=20)$. Daylight hours are from half an hour before sunrise to half an hour after sunset.

strenuous migration with possible detrimental carryover effects (Norris \& Marra, 2007) and predation and hunting pressures are presumably more acute in Africa than in Europe. As we cannot separate the contribution of these factors, a question is raised regarding the importance for stork survival of the behavioural differences that we have described. Schaub et al. (2005) showed that primary production during October-November in the Sahel region in Africa, where our focal storks also overwintered, explained $55-88 \%$ of the annual survival of juvenile white storks. Similar findings were also found in juvenile Egyptian vultures, Neophron percnopterus, and lesser kestrels, Falco naumanni (Grande et al., 2009; Mihoub, Gimenez, Pilard, \& Sarrazin, 2010). These studies emphasized that food availability during early overwintering is a key factor for yearly juvenile survival. In the light of these findings, the differences in foraging costs, energy expenditure and habitat use seem highly relevant to juvenile stork survival.

In addition to overwintering implications, we investigated what caused certain individuals to overwinter in Europe rather than in Africa. We found that EUW juveniles started migrating later as they hatched later than AFW juveniles. Nevertheless, they did not migrate at a younger age or with less experience suggesting that immaturity or unpreparedness was not the main reason for shortening migration. Rather, we suggest that the reason might be linked to social migration aspects. Storks are considered obligate social migrants such that juveniles need to fly in flocks with experienced adults to accomplish the migration (Chernetsov, Berthold, \& Querner, 2004). Recent findings, however, suggest that juveniles are unable to remain in the same flock with the adults due to inferior flight skills, thus falling behind and joining subsequent flocks throughout their journey (Rotics et al., 2016). Late-migrating juveniles might have a higher probability of wintering in Europe after failing to join subsequent flocks as a result of travelling much later than peak migration time. Accordingly, three of our studied EUW storks were observed alone during autumn in Europe (local observations). Additionally, EUW juveniles showed an unusual pattern of frequent stopovers during migration,
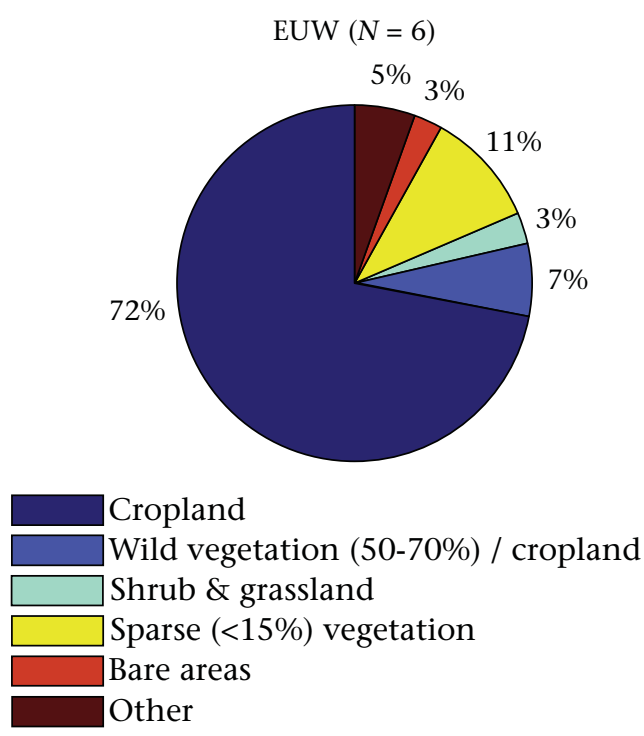

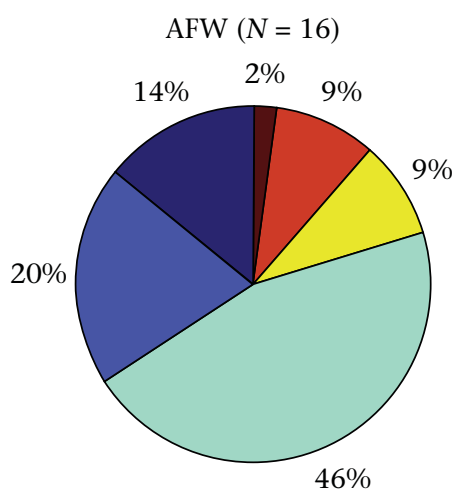

Figure 4. Habitat use of storks wintering in Europe (EUW) versus Africa (AFW). Land use data are based on ESA GlobCover 2009 (@ ESA 2010 and UCLouvain, http://due.esrin.esa. int/page_globcover.php). 


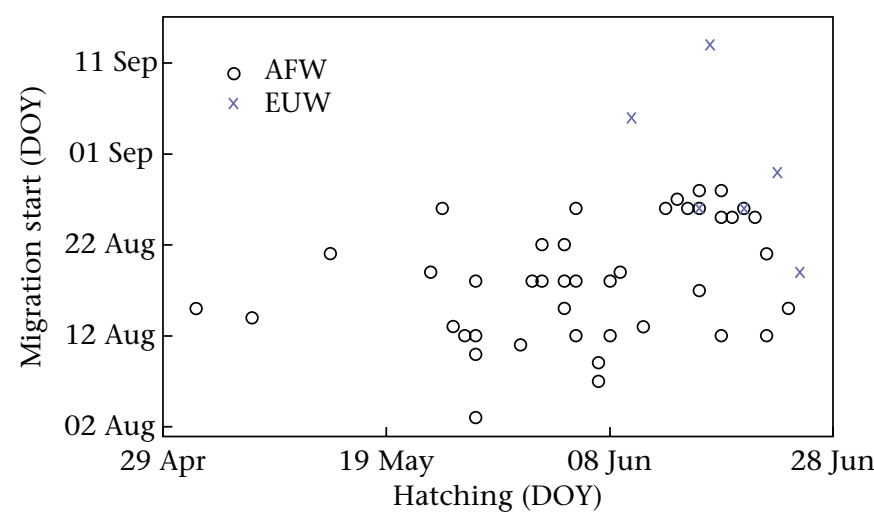

Figure 5. Hatching and migration start time of storks wintering in Europe (EUW) versus Africa (AFW). Data are day of year (DOY) with axis labels in day-month format.

unlike the nonstop migration of AFW juveniles (Appendix 5) and adult storks (Rotics et al., 2016), which could imply that they were not part of a flock.

Late-hatching EUW juveniles survived better than their AFW counterparts, which might seem unexpected considering that late hatching has commonly been associated with lower survival in numerous species (e.g.: Naef-Daenzer, Widmer, \& Nuber, 2001; Rodríguez, van Noordwijk, Álvarez, \& Barba, 2016; Saino et al., 2012; Saunders, Arnold, Roche, \& Cuthbert, 2014), including in storks that migrate to Africa (Rotics et al., 2017). We emphasize, however, that our results do not associate late hatching itself with increased survival, but rather, it may have a surprisingly advantageous outcome only under specific circumstances of staying in Europe. Curious findings showed that younger and weaker white stork nestlings in another population became the better breeders (Aguirre \& Vergara, 2007). The reason for this was not clear as the study was based on ringing data, but, in line with our findings, the researchers speculated that poor body condition inhibited the migration of these nestlings leading them to spend more time in their food-enriched natal grounds in Spain, which might have favourable implications.

Correspondingly, white storks that overwinter in Europe, and specifically in Spain, are increasing both in number and proportion (Barbraud, Barbraud, \& Barbraud, 1999; Gordo et al., 2007; Martín et al., 2016), and a similar trend has been reported in other species (Newton, 2008; Pavón-Jordán et al., 2015; Plummer et al., 2015). Previous studies elucidated overwintering conditions as the most important determinants of population dynamics (Gillings, Newson, Noble, \& Vickery, 2005; Goodenough et al., 2009; Ockendon et al., 2012), particularly affecting juveniles which are prone to higher mortality rates (Gunnarsson, Gill, Newton, Potts, \& Sutherland, 2005; Sanz-Aguilar, De Pablo, et al., 2015; Szostek \& Becker, 2015). More specifically, juvenile survival was found to be more important than breeding output in regulating the population size of storks and black kites, Milvus migrans (Schaub et al., 2005; Sergio et al., 2011). We therefore link our findings to population trends by suggesting that higher juvenile survival contributes to the recent increase in European overwintering storks, and further hypothesize that it is involved in the phenomenon of shortening migrations in Holarctic species (Newton, 2008).

The adaptive value of migration should exceed its risks and costs by providing access to higher resource availability (Alerstam et al., 2003; Somveille et al., 2015). Our data, however, showed that EUW juveniles avoided long-distance migration and benefited from overwintering in Europe. This raises the question of whether the majority of storks, which migrated to Africa, display suboptimal migratory behaviour. Our findings relate to the first-year period, although, in the long run, overwintering in Europe might not necessarily be the optimal option, possibly due to long-term detrimental effects of feeding on waste (Carneiro et al., 2015) or erratic effects of severe winters (Salewski et al., 2013; Sanz-Aguilar et al., 2012). Furthermore, survival benefits of overwintering in Europe may be restricted to juveniles and might even be reversed at older ages, as has been found in other birds (Sanz-Aguilar et al., 2012, Sanz-Aguilar, De Pablo, et al., 2015).

Similar to our findings, Lok et al. (2011) found a paradox in spoonbills, where the majority of the population overwinters in Africa, but overwintering in Europe yields higher survival. They suggested (among other explanations) an evolutionary gap between the spoonbills' actual and optimal behaviour. In storks and other social migrants, such a gap could be maintained by social learning from experienced individuals (Chernetsov et al., 2004). Accordingly, the fact that four of the six juvenile storks that wintered in Europe migrated to Africa in their second year and the finding that migration timing affected first-year overwintering location suggested no genetic basis was involved. Nevertheless, if such an evolutionary gap exists, the plastic nature of bird migration (Able \& Belthoff, 1998; Alerstam et al., 2003; Pulido \& Berthold, 2010) is expected to lead to a decrease in long-distance migratory behaviour, as has been reported extensively in recent years (Ambrosini et al., 2016; Gordo et al., 2007; Newton, 2008; PavónJordán et al., 2015; Ramo et al., 2015). Migratory shift, unless mitigated by density-dependent effects (Musilová, Musil, Zouhar, \& Romportl, 2015), may have a profound impact on migrants' population ecology with implications for abandoned and newly utilized ecosystems (Uno \& Power, 2015; Wood \& Pidgeon, 2015). However, caution should be taken when drawing such conclusions based on our case study as the results deal only with first-year juveniles and the data, despite their high quality and resolution, came from a rather modest number of individuals (especially for EUW storks). Furthermore, a European Union directive (1993/31/EC) to diminish open landfill activity, starting in 2016, will reduce the availability of this resource, which is expected to significantly decrease the suitability of European wintering grounds for white storks (Peris, 2003) and other species. It will be important to monitor the forthcoming effects on storks' population dynamics and life histories from scientific and conservation perspectives, specifically examining the plasticity of migratory behaviour in response to anthropogenic changes.

\section{Conclusions}

The few juvenile storks that overwintered in Europe attained higher survival than most individuals that wintered in Africa, possibly due to EUW storks' lower activity-related energy expenditure and reduced movement while relying more on anthropogenic resources. These results illuminate the contemporary trend of bird species to shorten migration distance and overwinter at higher latitudes, a phenomenon of potential colossal effects on migrant ecology.

\section{Acknowledgments}

We thank S. Wohlfahrt, A. Hinz, P. Wevers and M. Meinel from the University of Potsdam for conducting the field observations, T. Schaffer, H.G. Benecke and W. Sender and his crew in the Drömling Nature Park for their essential help in the field work in Germany, $\mathrm{H}$. Schmid, H. Eggers, G. Sterzer and N. Aljadeff for their help in the data downloading, R. Harel for advising in all the research aspects, O. Hatzofe from the Israel Nature and Parks Authority and B. Keeves from the Max-Planck-Institute for Ornithology for their help in retrieving lost transmitters and W. Heidrich and F. Kuemmeth from 
e-obs $\mathrm{GmbH}$ for their dedicated technical support. We acknowledge the generous funding of DIP grants (DFG) NA 846/1-1 and WI 3576/1-1 to R.N., F.J. and M.W. This study was also supported by the Minerva Center for Movement Ecology granted to R.N. S.R. was supported by a doctoral bird study scholarship of the Ministry of Science and Technology, Israel. D.Z. received funding from the People Programme (Marie Curie Actions) of the European Union's Seventh Framework Programme (FP7/2007-2013) under REA grant agreement no. 624958 .

\section{References}

Able, K. P., \& Belthoff, J. R. (1998). Rapid 'evolution' of migratory behaviour in the introduced house finch of eastern North America. Proceedings of the Royal Society B: Biological Sciences, 265(1410), 2063-2071.

Adriaensen, F., \& Dhondt, A. A. (1990). Population-dynamics and partial migration of the European robin (erithacus-rubecula) in different habitats. Journal of Animal Ecology, 59(3), 1077-1090. http://dx.doi.org/10.2307/5033.

Aguirre, J. I., \& Vergara, P. (2007). Younger, weaker white stork (Ciconia ciconia) nestlings become the best breeders. Evolutionary Ecology Research, 9(2), 355-364.

Alerstam, T., Hedenström, A., \& Åkesson, S. (2003). Long-distance migration: Evolution and determinants. Oikos, 103(2), 247-260. http://dx.doi.org/10.1034/ j.1600-0706.2003.12559.x.

Alves, J. A., Gunnarsson, T. G., Hayhow, D. B., Appleton, G. F., Potts, P. M., Sutherland, W. J., et al. (2013). Costs, benefits, and fitness consequences of different migratory strategies. Ecology, 94(1), 11-17.

Ambrosini, R., Cuervo, J. J., du Feu, C., Fiedler, W., Musitelli, F., Rubolini, D., et al. (2016). Migratory connectivity and effects of winter temperatures on migratory behaviour of the European robin Erithacus rubecula: A continent-wide analysis. Journal of Animal Ecology, 85(3), 749-760. http://dx.doi.org/10.1111/13652656.12497.

Barbraud, C., Barbraud, J. C., \& Barbraud, M. (1999). Population dynamics of the white stork Ciconia ciconia in western France. Ibis, 141(3), 469-479. http:|| dx.doi.org/10.1111/j.1474-919X.1999.tb04416.x.

Berthold, P. (1998). Bird migration: Genetic programs with high adaptability. Zoology-Analysis of Complex Systems, 101(4), 235-245.

Berthold, P., van den Bossche, W., Fiedler, W., Gorney, E., Kaatz, M., Leshem, Y., et al. (2001). The migration of the white stork (Ciconia ciconia): A special case according to new data. Journal of Ornithology, 142(1), 73-92.

Berthold, P., von der Bossche, W., Jakubiec, Z., Kaatz, C., Kaatz, M., \& Querner, U. (2002). Long-term satellite tracking sheds light upon variable migration strategies of White Storks (Ciconia ciconia). Journal of Ornithology, 143(4), 489-493. http://dx.doi.org/10.1007/bf02465604.

Bocheński, M., \& Jerzak, L. (2006). Behaviour of the white stork Ciconia ciconia: A review. In P. Tryjanowski, T. Sparks, \& L. Jerzak (Eds.), The White Stork in Poland: Studies in Biology, Ecology and Conservation (p. 315). Poznan, Poland: Bogucki Wydaw, Naukowe.

Both, C., Bouwhuis, S., Lessells, C. M., \& Visser, M. E. (2006). Climate change and population declines in a long-distance migratory bird. Nature, 441(7089), 81-83. http://dx.doi.org/10.1038/nature04539.

Brown, C. R., Roche, E. A., \& O'Brien, V. A. (2015). Costs and benefits of late nesting in cliff swallows. Oecologia, 177(2), 413-421. http://dx.doi.org/10.1007/s00442 014-3095-3.

Bruderer, B., Peter, D., Boldt, A., \& Liechti, F. (2010). Wing-beat characteristics of birds recorded with tracking radar and cine camera. Ibis, 152(2), 272-291.

Calenge, C. (2006). The package 'adehabitat' for the R software: A tool for the analysis of space and habitat use by animals. Ecological Modelling, 197(3-4), 516-519. http://dx.doi.org/10.1016/j.ecolmodel.2006.03.017.

Carneiro, M., Colaço, B., Brandão, R., Azorín, B., Nicolas, O., Colaço, J., et al. (2015) Assessment of the exposure to heavy metals in Griffon vultures (Gyps fulvus) from the Iberian Peninsula. Ecotoxicology and Environmental Safety, 113, 295-301. http://dx.doi.org/10.1016/j.ecoenv.2014.12.016.

Carrascal, L. M., Alonso, J. C., \& Alonso, J. A. (1990). Aggregation size and foraging behavior of white storks Ciconia-cinconia during the breeding-season. Ardea, $78(3), 399-404$

Charmantier, A., \& Gienapp, P. (2014). Climate change and timing of avian breeding and migration: Evolutionary versus plastic changes. Evolutionary Applications, 7(1), 15-28. http://dx.doi.org/10.1111/eva.12126.

Chernetsov, N., Berthold, P., \& Querner, U. (2004). Migratory orientation of first-year white storks (Ciconia ciconia): Inherited information and social interactions. Jour nal of Experimental Biology, 207(6), 937-943. http://dx.doi.org/10.1242/jeb.00853.

Cooper, N. W., Sherry, T. W., \& Marra, P. P. (2015). Experimental reduction of winte food decreases body condition and delays migration in a long-distance migratory bird. Ecology, 96(7), 1933-1942. http://dx.doi.org/10.1890/14-1365.1.

Daan, S., Deerenberg, C., \& Dijkstra, C. (1996). Increased daily work precipitates natural death in the kestrel. Journal of Animal Ecology, 65(5), 539-544. http:// dx.doi.org/10.2307/5734.

De Giacomo, U., \& Guerrieri, G. (2008). The feeding behavior of the Black Kite (Milvus migrans) in the rubbish dump of Rome. Journal of Raptor Research, 42(2), 110-118. http://dx.doi.org/10.3356/jrr-07-09.1.
Dodge, S., Bohrer, G., Weinzierl, R., Davidson, S., Kays, R., Douglas, D., et al. (2013). The environmental-data automated track annotation (Env-DATA) system: inking animal tracks with environmental data. Movement Ecology, 1(1), 3.

Duriez, O., Ens, B. J., Choquet, R., Pradel, R., \& Klaassen, M. (2012). Comparing the seasonal survival of resident and migratory oystercatchers: Carry-over effects of habitat quality and weather conditions. Oikos, 121(6), 862-873. http:// dx.doi.org/10.1111/j.1600-0706.2012.20326.x.

Flack, A., Fiedler, W., Blas, J., Pokrovsky, I., Kaatz, M., Mitropolsky, M., et al. (2016). Costs of migratory decisions: A comparison across eight white stork populations. Science Advances, 2(1). http://dx.doi.org/10.1126/sciadv.1500931.

Getz, W. M., Fortmann-Roe, S., Cross, P. C., Lyons, A. J., Ryan, S. J., \& Wilmers, C. C. (2007). LoCoH: Nonparameteric kernel methods for constructing home ranges and utilization distributions. Plos One, 2(2), e207. http://dx.doi.org/10.1371/ journal.pone.0000207.

Gillings, S., Newson, S. E., Noble, D. G., \& Vickery, J. A. (2005). Winter availability of cereal stubbles attracts declining farmland birds and positively influences breeding population trends. Proceedings of the Royal Society B: Biological Sciences, 272(1564), 733-739. http://dx.doi.org/10.1098/rspb.2004.3010.

Goodenough, A. E., Elliot, S. L., \& Hart, A. G. (2009). The challenges of conservation for declining migrants: Are reserve-based initiatives during the breeding season appropriate for the Pied Flycatcher Ficedula hypoleuca? Ibis, 151(3), 429-439.

Gordo, O., Sanz, J. J., \& Lobo, J. M. (2007). Spatial patterns of white stork (Ciconia ciconia) migratory phenology in the Iberian Peninsula. Journal of Ornithology, 148(3), 293-308. http://dx.doi.org/10.1007/s10336-007-0132-6.

Grande, J. M. Serrano, D. Tavecchia, G., Carrete, M. Ceballos, O., Díaz-Delgado, R et al. (2009). Survival in a long-lived territorial migrant: Effects of life-history traits and ecological conditions in wintering and breeding areas. Oikos, 118(4), 580-590. http://dx.doi.org/10.1111/j.1600-0706.2009.17218.x.

Greenwood, P. J. (1980). Mating systems, philopatry and dispersal in birds and mammals. Animal Behaviour, 28(NOV), 1140-1162. http://dx.doi.org/10.1016 50003-3472(80)80103-5.

Gunnarsson, T. G., Gill, J. A., Newton, J., Potts, P. M., \& Sutherland, W. J. (2005) Seasonal matching of habitat quality and fitness in a migratory bird. Proceedings of the Royal Society B: Biological Sciences, 272(1578), 2319-2323. http:/ dx.doi.org/10.1098/rspb.2005.3214.

Halsey, L. G., Shepard, E. L. C., Hulston, C. J., Venables, M. C., White, C. R. Jeukendrup, A. E., et al. (2008). Acceleration versus heart rate for estimating energy expenditure and speed during locomotion in animals: Tests with an easy model species, Homo sapiens. Zoology, 111(3), 231-241. http://dx.doi.org/ 10.1016/j.zool.2007.07.011.

Hüppop, O., \& Hüppop, K. (2003). North Atlantic oscillation and timing of spring migration in birds. Proceedings of the Royal Society B: Biological Sciences, 270(1512), 233-240. http://dx.doi.org/10.1098/rspb.2002.2236.

PCC (2014). In R. K. P. a. L A. M. Core Writing Team (Ed.), Climate Change 2014 Synthesis Report. Contribution of Working Groups I, II and III to the Fifth Assessment Report of the Intergovernmental Panel on Climate Change (pp. 40-44). Geneva, Switzerland: IPCC.

Lok, T., Overdijk, O., Tinbergen, J. M., \& Piersma, T. (2011). The paradox of spoonbill migration: Most birds travel to where survival rates are lowest. Animal Behaviour, 82(4), 837-844. http://dx.doi.org/10.1016/j.anbehav.2011.07.019.

Marra, P. P., Francis, C. M., Mulvihill, R. S., \& Moore, F. R. (2005). The influence of climate on the timing and rate of spring bird migration. Oecologia, 142(2) 307-315. http://dx.doi.org/10.1007/s00442-004-1725-x.

Martín, B., Onrubia, A., de la Cruz, A., \& Ferrer, M. (2016). Trends of autumn counts at Iberian migration bottlenecks as a tool for monitoring continental populations of soaring birds in Europe. Biodiversity and Conservation, 25(2), 295-309. http://dx.doi.org/10.1007/s10531-016-1047-4.

Mata, A., Caloin, M., Michard-Picamelot, D., Ancel, A., \& Le Maho, Y.(2001). Are nonmigrant white storks (Ciconia ciconia) able to survive a cold-induced fast? Comparative Biochemistry and Physiology a-Molecular and Integrative Physiology, 130(1), 93-104. http://dx.doi.org/10.1016/s1095-6433(01)00366-x.

Mata, A., Massemin-Challet, S., Caloin, M., Michard-Picamelot, D., \& Le Maho, Y. (2010). Seasonal variation in energy expenditure and body composition in captive White Storks (Ciconia ciconia). Comparative Biochemistry and Physiology a-Molecular \& Integrative Physiology, 155(1), 19-24. http://dx.doi.org/10.1016/ j.cbpa.2009.08.019.

McKellar, A. E., Marra, P. P., Hannon, S. J., Studds, C. E., \& Ratcliffe, L. M. (2013) Winter rainfall predicts phenology in widely separated populations of a migrant songbird. Oecologia, 172(2), 595-605. http://dx.doi.org/10.1007/s00442-0122520-8.

McKim-Louder, M. I., Hoover, J. P., Benson, T. J., \& Schelsky, W. M. (2013). Juvenile survival in a neotropical migratory songbird is lower than expected. PLoS One, 8(2), e56059. http://dx.doi.org/10.1371/journal.pone.0056059.

Mihoub, J. B., Gimenez, O., Pilard, P., \& Sarrazin, F. (2010). Challenging conservation of migratory species: Sahelian rainfalls drive first-year survival of the vulnerable Lesser Kestrel Falco naumanni. Biological Conservation, 143(4), 839-847. http://dx.doi.org/10.1016/j.biocon.2009.12.026.

Mitchell, G. W., Guglielmo, C. G., Wheelwright, N. T., Freeman-Gallant, C. R. \& Norris, D. R. (2011). Early life events carry over to influence pre-migratory condition in a free-living songbird. PLoS One, 6(12), e28838. http://dx.doi.org/ 10.1371/journal.pone.0028838.

Musilová, Z. Musil, P. Zouhar, J. \& Romportl, D. (2015). Long-term trends, total numbers and species richness of increasing waterbird populations at sites on the edge of their winter range: Cold-weather refuge sites are more important 
than protected sites. Journal of Ornithology, 156(4), 923-932. http://dx.doi.org/ 10.1007/s10336-015-1223-4.

Naef-Daenzer, B., Widmer, F., \& Nuber, M. (2001). Differential post-fledging survival of great and coal tits in relation to their condition and fledging date.Journal of Animal Ecology, 70(5), 730-738. http://dx.doi.org/10.1046/j.0021-8790.2001.00533.x.

Newton, I. (2008). Recent changes in bird migrations. In I. Newton (Ed.), The migration ecology of birds (pp. 617-637). London, U.K.: Elsevier.

Norris, D. R., \& Marra, P. P. (2007). Seasonal interactions, habitat quality, and population dynamics in migratory birds. Condor, 109(3), 535-547.

Ockendon, N., Hewson, C. M., Johnston, A., \& Atkinson, P. W. (2012). Declines in British-breeding populations of Afro-Palaearctic migrant birds are linked to bioclimatic wintering zone in Africa, possibly via constraints on arrival time advancement. Bird Study, 59(2), 111-125. http://dx.doi.org/10.1080/ 00063657.2011.645798.

Oro, D., Genovart, M., Tavecchia, G., Fowler, M. S., \& Martínez-Abraín, A. (2013). Ecological and evolutionary implications of food subsidies from humans. Ecology Letters, 16(12), 1501-1514. http://dx.doi.org/10.1111/ele.12187.

Pavón-Jordán, D., Fox, A. D., Clausen, P., Dagys, M., Deceuninck, B., Devos, K., et al. (2015). Climate-driven changes in winter abundance of a migratory waterbird in relation to EU protected areas. Diversity and Distributions, 21(5), 571-582. http://dx.doi.org/10.1111/ddi.12300.

Pawlowicz R. (2009). SUNCYCLE code adapted from: AIR SEA TOOLBOX (version 2.0: 8/9/99) based on Appendix E in the 1978 edition of Almanac for Computers, Nautical Almanac Office, U.S. Naval Observatory. Washington, D.C.: U.S. Government Printing Office.

Peris, S. J. (2003). Feeding in urban refuse dumps: Ingestion of plastic objects by the White Stork (Ciconia ciconia). Ardeola, 50(1), 81-84.

Plummer, K. E., Siriwardena, G. M., Conway, G. J., Risely, K., \& Toms, M. P. (2015). Is supplementary feeding in gardens a driver of evolutionary change in a migratory bird species? Global Change Biology, 21(12), 4353-4363. http://dx.doi.org/ $10.1111 /$ gcb.13070.

Pulido, F., \& Berthold, P. (2010). Current selection for lower migratory activity will drive the evolution of residency in a migratory bird population. Proceedings of the National Academy of Sciences of the United States of America, 107(16), 7341-7346. http://dx.doi.org/10.1073/pnas.0910361107.

R Core Team. (2016). R: A Language and Environment for Statistical Computing. Vienna, Austria: R Foundation for Statistical Computing.

Ramo, C., Amat, J. A., Nilsson, L., Schricke, V., Rodríguez-Alonso, M., GómezCrespo, E., et al. (2015). Latitudinal-related variation in wintering population trends of greylag geese (Anser Anser) along the atlantic flyway: A response to climate change? PLoS One, 10(10), e0140181. http://dx.doi.org/10.1371/ journal.pone.0140181.

Ramos, R., Ramírez, F., Sanpera, C., Jover, L., \& Ruiz, X. (2009). Diet of yellow-legged gull (Larus michahellis) chicks along the Spanish Western Mediterranean coast: The relevance of refuse dumps. Journal of Ornithology, 150(1), 265-272. http:// dx.doi.org/10.1007/s10336-008-0346-2.

Rodríguez, S., van Noordwijk, A. J., Álvarez, E., \& Barba, E. (2016). A recipe for postfledging survival in great tits Parus major: Be large and be early (but not too much). Ecology and Evolution, 6(13), 4458-4467. http://dx.doi.org/10.1002/ ece3.2192.

Rotics, S., Kaatz, M., Resheff, Y. S., Feldman, S., Zurell, D., Sapir, N., et al. (2016). The challenges of the first migration: Movement and behaviour of juvenile vs. adult white storks with insights regarding juvenile mortality. Journal of Animal Ecology, 85(4), 938-947, http://dx.doi.org/10.1111/1365-2656.12525.

Rotics, S., Kaatz, M., Resheff, Y. S., Feldman, S., Zurell, D., Sapir, N., et al. (2017). Earlylife attributes predict first-year survival in a long-distance migrant (Manuscript in preparation)

Saino, N., Romano, M., Ambrosini, R., Rubolini, D., Boncoraglio, G., Caprioli, M., et al. (2012). Longevity and lifetime reproductive success of barn swallow offspring are predicted by their hatching date and phenotypic quality. Journal of Animal Ecology, 81(5), 1004-1012. http://dx.doi.org/10.1111/j.1365-2656.2012.01989.x.

Sala, J. E., Wilson, R. P., \& Quintana, F. (2015). Foraging effort in Magellanic penguins: Balancing the energy books for survival? Marine Biology, 162(3), 501-514. http://dx.doi.org/10.1007/s00227-014-2581-9.

Salewski, V., Hochachka, W. M., \& Fiedler, W. (2013). Multiple weather factors affect apparent survival of European passerine birds. PLoS One, 8(4), e59110. http:// dx.doi.org/10.1371/journal.pone.0059110.

Sanz-Aguilar, A., Béchet, A., Germain, C., Johnson, A. R., \& Pradel, R. (2012). To leave or not to leave: Survival trade-offs between different migratory strategies in the greater flamingo. Journal of Animal Ecology, 81(6), 1171-1182. http://dx.doi.org/ 10.1111/j.1365-2656.2012.01997.x.

Sanz-Aguilar, A., De Pablo, F., \& Donázar, J. A. (2015). Age-dependent survival of island vs. mainland populations of two avian scavengers: Delving into migration costs. Oecologia, 179(2), 405-414. http://dx.doi.org/10.1007/s00442-0153355-x.

Sanz-Aguilar, A., Jovani, R., Melián, C. J., Pradel, R., \& Tella, J. L. (2015). Multi-event capture-recapture analysis reveals individual foraging specialization in a generalist species. Ecology, 96(6), 1650-1660. http://dx.doi.org/10.1890/140437.1.

Saunders, S. P., Arnold, T. W., Roche, E. A., \& Cuthbert, F. J. (2014). Age-specific survival and recruitment of piping plovers Charadrius melodus in the Great Lakes region. Journal of Avian Biology, 45(5), 437-449. http://dx.doi.org/10.1111/ jav.00319.

Schaub, M., Kania, W., \& Köppen, U. (2005). Variation of primary production during winter induces synchrony in survival rates in migratory white storks Ciconia ciconia. Journal of Animal Ecology, 74(4), 656-666. http://dx.doi.org/10.1111/ j.1365-2656.2005.00961.x.

Sergio, F., Tavecchia, G., Blas, J., López, L., Tanferna, A.\& \& Hiraldo, F. (2011). Variation in age-structured vital rates of a long-lived raptor: Implications for population growth. Basic and Applied Ecology, 12(2), 107-115. http://dx.doi.org/10.1016/ j.baae.2010.11.004.

Shephard, J. M., Rycken, S., Almalik, O., Struyf, K., \& Van Erp-van der Kooij, L. (2015). Migration strategies revealed by satellite tracking among descendants of a population of European white stork (Ciconia ciconia) reintroduced to Belgium. Journal of Ornithology, 156(4), 943-953. http://dx.doi.org/10.1007/s10336-0151204-7.

Somveille, M., Rodrigues, A. S. L., \& Manica, A. (2015). Why do birds migrate? A macroecological perspective. Global Ecology and Biogeography, 24(6), 664-674. http://dx.doi.org/10.1111/geb.12298.

Swanson, D. L., \& Olmstead, K. L. (1999). Evidence for a proximate influence of winter temperature on metabolism in passerine birds. Physiological and Biochemical Zoology, 72(5), 566-575. http://dx.doi.org/10.1086/316696.

Swanson, D. L., \& Weinacht, D. P. (1997). Seasonal effects on metabolism and thermoregulation in northern bobwhite. Condor, 99(2), 478-489. http:// dx.doi.org/10.2307/1369954.

Szostek, K. L., \& Becker, P. H. (2015). Survival and local recruitment are driven by environmental carry-over effects from the wintering area in a migratory seabird. Oecologia, 178(3), 643-657. http://dx.doi.org/10.1007/s00442-0153298-2.

Tortosa, F. S., Caballero, J. M., \& Reyes-López, J. (2002). Effect of rubbish dumps on breeding success in the White Stork in southern Spain. Waterbirds, 25(1), 39-43. http://dx doi.org/10.1675/1524-4695(2002)025[0039:eordob]2.0.co:2.

Tsachalidis, E. P., \& Goutner, V. (2002). Diet of the white stork in Greece in relation to habitat. Waterbirds, 25(4), 417-423. http://dx.doi.org/10.1675/15244695(2002)025[0417:dotwsi]2.0.co;2.

Tsachalidis, E. P., Liordos, V., \& Goutner, V. (2005). Growth of white stork Ciconia ciconia nestlings. Ardea, 93(1), 133-137.

Turrin, C., Watts, B. D., \& Mojica, E. K. (2015). Landfill use by bald eagles in the chesapeake bay region. Journal of Raptor Research, 49(3), 239-249.

Uno, H., \& Power, M. E. (2015). Mainstem-tributary linkages by mayfly migration help sustain salmonids in a warming river network. Ecology Letters, 18(10), 1012-1020. http://dx.doi.org/10.1111/ele.12483.

Visser, M. E., Perdeck, A. C., van Balen, J. H., \& Both, C. (2009). Climate change leads to decreasing bird migration distances. Global Change Biology, 15(8), 1859-1865. http://dx.doi.org/10.1111/j.1365-2486.2009.01865.x.

Wilson, R. P., White, C. R., Quintana, F., Halsey, L. G., Liebsch, N., Martin, G. R., et al. (2006). Moving towards acceleration for estimates of activity-specific metabolic rate in free-living animals: The case of the cormorant. Journal of Animal Ecology, 75(5), 1081-1090. http://dx.doi.org/10.1111/j.1365-2656.2006.01127.x.

Wood, E. M., \& Pidgeon, A. M. (2015). Extreme variations in spring temperature affect ecosystem regulating services provided by birds during migration. Ecosphere, 6(11), art216. http://dx.doi.org/10.1890/es15-00397.1.

\section{Appendix 1. Individuals that did not reach the wintering period}

From a total of 92 tagged juveniles, four died on the first day of fledging and 25 died or disappeared (see definition of 'missing' in Methods) during the autumn migration (18 of them after crossing Europe). These individuals were omitted as their wintering site and wintering behaviour could not be addressed. Additionally, nine individuals that died during the first month of wintering (October) were also excluded. These mortality events all occurred in Africa, and could be largely related to migratory carryover effects rather than wintering conditions. We took a conservative approach and excluded these individuals to mitigate these migratory effects, as we aimed to concentrate on wintering-site effects on survival

\section{Appendix 2. Data acquisition}

Microwave tags transmitted two to four GPS fixes per day via satellite communication. E-obs tags sent two SMSs each day containing five GPS fixes with a $1 \mathrm{~h}$ interval. E-obs tags also logged high-resolution data of GPS and ACC that could be downloaded via a UHF radio link from approximately $300 \mathrm{~m}$. To download data, we followed the storks in their natal areas, during the autumn migration from Germany to Turkey, and while passing through Israel. Additionally, data were obtained from retrieved transmitters of dead storks. 


\section{Appendix 3. Data subsampling}

We compared data from solar-charged transmitters of white storks wintering in Europe and in Africa. However, solar power in Europe was considerably lower resulting in more fragmented data with lower resolution than wintering data from Africa. To account for this bias, we subsampled the African wintering (AFW) storks' data in line with sampling rates of European wintering (EUW) storks' data using the following steps. (1) Each AFW stork was randomly paired with one EUW stork. Because we had data from six EUW and 16 AFW storks, each EUW stork was paired with three or four AFW storks. (2) Data time stamps were rounded down to 5 min values, i.e. a time stamp of 1733 was adjusted to 1730 . (3) Within each pair, data were sorted first by the time stamp and then by a unique number representing the individual (bird ID). This resulted in a combination of records from both individuals sorted by time and ID. As long as both transmitters recorded data continuously, we had a record from one individual following a record from the other individual for every time stamp. However, when one of the tags stopped recording (due to low solar power), we got a series of records of the same individual (mostly the AFW individual). (4) We omitted all sequential records of the same individual which yielded a data set in which each sequential pair of records was always from the two individuals. As a result, we achieved the same number of records with the same time and data resolution for each individual. In this way, we subsampled the AFW individual to generate exactly the same data set as the more fragmented data of the EUW individual.

\section{Appendix 4. Deducing mortality of 'missing' storks}

The e-obs transmitters relied on cellular communication, which resulted in 14 cases of missing storks: individuals that stopped sending data without an indication of mortality. No signal was received from any missing storks for more than 18 months. The possibility that during all this extended time they were ranging in an area without cellular coverage is unlikely because during spring migration they should have returned to areas with reception. In addition, storks were moving extensively and cellular coverage was overall good even in many remote regions in Africa. We argue that these storks probably died during wintering in an area without reception. Other alternatives seem less likely. (1) The chances that the transmitter fell off the stork are very low. While tagging, we do not leave a 'weak link' in the harness and after tagging more than 300 storks using the same method over the past 25 years (Berthold et al., 2002) we have never encountered such a case (M. Kaatz, personal observation). (2) We assume that the e-obs transmitters' failure rates during the first year of deployment were low. In another study (Rotics et al., 2016) we tagged adult storks with similar e-obs transmitters and could locate them, even if transmitters malfunctioned, because of the adults' high nest fidelity (Barbraud et al., 1999). The rate of first-year tag malfunction in these adults was $9.5 \%$ (four of 42 ). (3) In all four cases that transmitters reappeared and started sending data after more than 4 months of 'absence', the storks were found to be dead. Therefore, we assume that $90 \%$ of the missing storks might be better referred to as dead.

\section{Appendix 5. Migration stopover patterns}

We examined high-resolution data from the first 10 days after migration onset (definition in Methods) for individuals that reached their wintering grounds (EUW: $N=6$; AFW: $N=31$ ) in order to understand possible reasons for EUW storks halting migration. Migration progress days were defined as days of more than $100 \mathrm{~km}$ displacement and stopover days were days with less than $30 \mathrm{~km}$ displacement (average daily displacement during migration is $273 \pm 96 \mathrm{~km}$, Rotics et al., 2016). EUW storks stopped migration after an average of 2.3 days and spent most of the 10 days at stopover sites compared to AFW storks which rarely stopped after migration onset (EUW median stopover days: 7; AFW: 0; Wilcoxon rank sum test: $z=3.86, N=37, P<0.001$ ).

Table A1

The relationship between the land use classes used in Fig. 4 and their underlying GlobCover land classes

\begin{tabular}{|c|c|}
\hline Land class used & GlobCover land classes (code) \\
\hline \multirow[t]{3}{*}{ Cropland } & Postflooding or irrigated croplands (11) \\
\hline & Rainfed croplands (14) \\
\hline & Mosaic cropland (50-70\%)/vegetation (20-50\%) (20) \\
\hline $\begin{array}{l}\text { Wild vegetation/ } \\
\text { cropland }\end{array}$ & Mosaic vegetation (50-70\%)/cropland (20-50\%) (30) \\
\hline \multirow[t]{4}{*}{ Shrub \& grassland } & $\begin{array}{l}\text { Mosaic forest or shrubland (50-70\%)/grassland } \\
(20-50 \%)(110)\end{array}$ \\
\hline & $\begin{array}{l}\text { Mosaic grassland }(50-70 \%) / \text { forest or shrubland } \\
(20-50 \%)(120)\end{array}$ \\
\hline & Closed to open (>15\%) shrubland (130) \\
\hline & Closed to open ( $>15 \%$ ) herbaceous vegetation (140) \\
\hline $\begin{array}{c}\text { Sparse }(<15 \%) \\
\text { vegetation }\end{array}$ & Sparse $(<15 \%)$ vegetation $(150)$ \\
\hline Bare areas & Bare areas (200) \\
\hline
\end{tabular}

In parentheses are the GlobCover land codes. For more details on GlobCover classes see http://due.esrin.esa.int/page_GlobCover.php.

Table A2

Comparisons between EUW and AFW storks of overall dynamic body acceleration (ODBA) and behavioural proportions during daylight hours on stationary days

\begin{tabular}{lllll}
\hline Parameter & EUW $(N=6)$ & AFW $(N=16)$ & $t$ & $P$ \\
\hline ODBA $\left(\mathrm{m} / \mathrm{s}^{2}\right)$ & $1.62 \pm 0.11$ & $1.89 \pm 0.05$ & 3.13 & 0.005 \\
Relative flight time (\%) & $5.3 \pm 0.8$ & $15.8 \pm 1$ & 5.8 & $<0.001$ \\
Relative resting time (\%) & $53.6 \pm 4.2$ & $42.6 \pm 1.6$ & 3.1 & 0.006 \\
Relative foraging time (\%) & $41.1 \pm 5.7$ & $41.7 \pm 2.1$ & 0.12 & 0.91 \\
\hline
\end{tabular}

Mean \pm SE are reported. Statistical results are for Student's $t$ tests $(d f=20)$. Daylight hours are from half an hour before sunrise to half an hour after sunset. Stationary days: less than $10 \mathrm{~km}$ daily displacement. 